Research Journal of Environmental and Earth Sciences 12(2): 19-28, 2020

DOI: $10.19026 /$ rjees. 12.6048

ISSN: 2041-0484; e-ISSN: 2041-0492

(C) 2020 Maxwell Scientific Publication Corp.

Submitted: February 27, 2020

Accepted: April 30, 2020

Published: August 25, 2020

\title{
Research Article \\ Community Perception and Adoption of Improved Sanitation in Tunduru District, Tanzania
}

\author{
${ }^{1}$ John G. Safari, ${ }^{2}$ Fauza I. Issa and ${ }^{1}$ Zacharia S. Masanyiwa \\ ${ }^{1}$ Institute of Rural Development Planning, P.O. Box 138, Dodoma, Tanzania \\ ${ }^{2}$ Kilwa District Council, P.O. Box 160, Lindi, Tanzania
}

\begin{abstract}
This study was conducted in Tunduru District, Tanzania to assess the perception and determinants for the adoption of improved sanitation. The specific objectives were twofold: (i) to examine community perception on improved sanitation and (ii) to determine the factors influencing the adoption of improved sanitation. A total of 248 householders were enrolled in the study. Data were collected through a household survey, key informant interviews, and focus group discussions. Quantitative data were subjected to t-test, Principal Component Analysis, and Chisquare test analysis. The findings showed that households with improved sanitation constituted $69.4 \%$ of the periurban sample compared with $18.9 \%$ for rural households. The corresponding figures for handwashing facilities were 3.1 and $5.8 \%$. The perceived benefits of improved sanitation were clustered into four dimensions reflecting comfort, convenience, status symbol, and disease prevention. The main factors explaining the adoption of improved sanitation were younger age of household heads, secondary or higher education, employment or engaging in small business, higher household economic status, and living in peri-urban areas. Overall, these factors relate to the behavioral, normative, and control beliefs, which guide individual's behavior and decisions to adopt and use improved toilet facilities.
\end{abstract}

Keywords: Behavior, hygiene, latrine, norms, perception, sanitation

\section{INTRODUCTION}

The importance of strengthening sanitation service delivery is well recognized due to increasing evidence of the relationship between appropriate sanitation and the protection of public health (Harter et al., 2019; Behera et al., 2020; Chung and Hellberg, 2020). A systematic review of the impact of sanitation found that increasing access to safe sanitation services can reduce diarrheal diseases by $16 \%$ (Wolf et al., 2014). Nonetheless, poor sanitation and hygiene practices are among the main causes of ill health and socio-economic problems that present a major development obstacle (Prüss-Ustün et al., 2014; Sclar et al., 2017). It is estimated that 2.35 billion people still lack access to basic sanitation services globally (WHO/UNICEF, 2017). Although sanitation is acknowledged as an indispensable element of disease prevention, studies in low-income countries show low achievement in sanitation interventions (Augsburg and RodriguezLesmes, 2018; Armah et al., 2018). This situation has drawn global attention; calling for more commitments towards improved sanitation. For instance, the Sustainable Development Goals (SDGs) emphasize improved access to clean water and sanitation by 2030 .
In particular, Goal 6 of the SDGs aims 'to ensure availability and sustainable management of water and sanitation for all', with target 6.2 explicitly aiming at achieving universal and equitable access to adequate and equitable sanitation and hygiene for all and end open defecation by 2030 (UNICEF and WHO, 2016).

Studies in Tanzania, however, show limited success in achieving sanitation access for all despite the new emphasis and its significance on health and the well-being (Jiménez et al., 2014; Seleman and Bhat, 2016). Based on survey data conducted in 2015, only $34.9 \%$ of households in urban areas and $9.8 \%$ in rural areas had access to improved sanitation facilities that were not shared while the corresponding figures for handwashing facilities with soap and water were 72 and $52 \%$ (URT, 2016). This implies that a significant proportion of the dwellers are at risk of contracting diseases related to poor sanitation and hygiene. Statistics also show that about 1\% of GDP is lost every year due to premature death, illness, lost time and productivity and that the economic burden of poor sanitation falls most heavily on the poor (WSP, 2012). While existing literature provides insights of the consequences of poor sanitation, knowledge is still limited with respect to the key drivers of low uptake of 
improved sanitation package. It is, however, generally understood that adoption of any technology and in this case of improved sanitation, is largely associated with people's perceptions and attitudes (Omambia, 2010; Alemu et al., 2017; Poortvliet et al., 2018). As Mariwar and Drangert (2011) state: perceptions determine our behavior partly because what we perceive determines what we do next. It is urged that interventions are implemented under complex systems and outcomes of interventions are sensitive to various specifics of the natural and social environments (Novotný et al., 2018). Understanding the contexts in which sanitation interventions are implemented is essential in informing the Community Total-Led Sanitaion (CLTS) initiatives so as to make them sensitive to the underlying determinants of sanitation adoption.

This study, therefore, assessed community perception and the determinants for the adoption of improved sanitation in rural and peri-urban areas of Tunduru District. The specific objectives of the study were twofold:

- To examine community perception on improved sanitation

- To determine the factors influencing the adoption of improved sanitation

Theoretical framework: The study was guided by Ajzen's (2002) theory of planned behavior. This theory provides a framework for studying human action. According to Ajzen, human behavior is guided by three kinds of considerations; beliefs about the likely outcomes of the behavior and the evaluations of the outcomes (behavioral beliefs), beliefs about the normative expectations of others and motivation to comply with these expectations (normative beliefs) and beliefs about the presence of factors that may facilitate or impede the performance of the behavior (control beliefs) (Mariwar and Drangert, 2011). The theory is relevant to this study because people's perceptions of sanitation and hygiene are likely to be influenced by their knowledge, beliefs, values and norms.

\section{METHODOLOGY}

Study area: The data presented in this paper were derived from an empirical study, which was conducted in Tunduru District in the South-Eastern part of Ruvuma Region. The District lies between latitudes 100 $15^{\prime}$ and $11045^{\prime}$ South of the Equator and between longitudes $36030^{\prime}$ and 380 East of Greenwich. It boarders Namtumbo District to the West, Liwale District (Lindi region) to the North and Nachingwea District (Lindi region) and Masasi District (Mtwara region) to the East. In the South, the district borders Ruvuma River which forms a physical international boundary with Mozambique. Tunduru District has a total area of $18,778 \mathrm{~km}^{2}$ of which $142.4 \mathrm{~km}^{2}(2.2 \%)$ is covered by water bodies (Tunduru District Council, 2018). This study involved four sites within the District: two in rural settings (Chingulungulu and Temeke) and two in peri-urban areas (Muhuwesi and Nakapanya). These sites were selected to provide a wide range of settlement diversity in order to capture contrasting experiences between rural and peri-urban settings.

Data collection: Data were drawn from 248 households in a cross-sectional survey carried out between May and August 2019. The study involved a combination of household surveys, Focus Group Discussions (FGD) and key informant interviews. The selection of households was based on systematic random sampling procedures based on the official list of households obtained from village leaders. The sample size was estimated through a proportionate sampling technique described in Miah (2016) as follows:

$$
\begin{aligned}
& n=\frac{N \sum N_{h} P_{h} Q_{h}}{N^{2} D^{2}+\sum N_{h} P_{h} Q_{h}} \\
& n_{h}=\frac{N_{h}}{N} * n
\end{aligned}
$$

where,

$n=$ Total sample size

$n_{h}=$ Sample size for $h$ stratum (rural or peri-urban)

$N=$ Total population (3170)

$N_{h}=$ Population size of $h$ stratum

$P_{h}=$ Proportion of households with improved sanitation in $h$ stratum (0.5)

$Q_{h}=1-P_{h}$

$D=\mathrm{d} / \mathrm{z}$

$d=$ Precision (error) $=0.05$

$\mathrm{z}=1.96(95 \%$, confidence interval)

A sample of 248 households was estimated using Eq. (1). The proportionate sample size of households in rural and peri-urban areas was calculated using Eq. (2) resulting in 127 and 121 households in rural and periurban areas, respectively.

Survey data were collected using a structured questionnaire with both closed and open-ended questions. The questionnaire consisted of four parts: general characteristics of respondents, availability of sanitation facilities at home, factors associated with improved sanitation and community perception towards improved sanitation measured against 17 deductive arguments. The measurement involved the use of threepoint Likert scale questions ranging from 'disagree' through 'neither agree nor disagree' to 'agree' as 
proposed by Wyatt and Meyers (1987). Questions were also set to assess household economic status through proxy indicators. These included an iron sheet roof, cement bricks, concrete floor, farm, television and bicycle. A household scored " 1 " if it possessed an item or " 0 " if it didn't. Further, in-depth interviews were conducted with the district health officer, Ward Executive Officers and Village Executive Officers. Focus group discussions of men and women ranging from 7 to 10 members were conducted in each village using a checklist with open-ended questions. This method helped to generate qualitative data by capturing the views of local people on perceptions towards improved sanitation.

Data analysis: Quantitative data were analyzed by using IBM-Statistical Package for Social Sciences (SPSS) software version 20. Descriptive statistics were performed on distribution of respondents by socioeconomic and demographic characteristics, availability of sanitation facilities and access to technical advice. Regarding economic status, a composite index was constructed based on the presence or absence of household assets or items. Thus, the possible maximum score for the household was 6 for householders that responded "yes" to all items and the minimum score was 0 for those that responded "no" to all items. A household was categorized as "poor" if it possessed $\leq 3$ items or "non-poor" if it owned 4-6 items. The constructed index was used to examine its relationship with the adoption of improved sanitation.

The World Health Organization (WHO) and the United Nations Children's Fund (UNICEF) through the Joint Monitoring Programme (JMP), define 'improved sanitation' as a sewer system, septic tank or pit latrine, Ventilated Improved Pit latrine (VIP), composting latrine or pit latrine with a slab that is not shared with other households (WHO/UNICEF, 2012). The defining feature of improved latrine or any such facility is its ability to ensure hygienic separation of human excreta from human contacts. In Tanzania, however, the improved toilet has the following attributes: walls not transparent, intact roofing materials, washable floor, a door that closes completely and not shared. Additional characteristics of the improved toilet are: having a sink and vent and toilet connected with a septic tank. Accordingly, latrines are categorized as type $\mathrm{X}=$ no latrine, type $\mathrm{A}=$ unimproved latrine, type $\mathrm{B}=$ improved pit latrine, type $C=$ Ventilated Improved Latrine (VIP) and Type $\mathrm{D}=$ pour flush toilet connected with a septic tank (URT, 2015). In this study, we used the national definition of the improved toilet and, therefore, a household owning type B, C or D was considered as having an "improved" toilet, otherwise "unimproved". The Student's independent samples t-test was used to compare mean scores for the perception of improved toilets. Principal Component Analysis (PCA) was performed to reduce the multidimensionality on the adoption of improved toilets. Thus, cases included in the analysis were only those for which the type of toilet was "improved". Through this analysis, it was possible to identify the underlying cluster of variables or explanatory constructs. The Kaiser-Meyer-Oklin measure of sampling adequacy and Bartlett's test of sphericity $(p=0.00)$ confirmed the suitability of the data for PCA as described by Field (2009). Chi-square test was used to compare the quality of toilets between rural and peri-urban households and to identify the demographic and socio-economic factors associated with the adoption of improved sanitation.

\section{RESULTS AND DISCUSSION}

Household characteristics: Household characteristics examined in this study included age, sex, household size, household income, education level, whether the household had ever been visited for advice and the type of latrine used by the household. The findings in Table 1 show that 6 in 10 respondents $(60.4 \%)$ were aged 36 or more years, with a higher proportion in the rural areas $(66.9 \%)$ than in the peri-urban villages $(53.7 \%)$. More than half of the respondents were women $(58.5 \%)$. About $75 \%$ (81.1\% in rural and $66.9 \%$ in peri-urban areas) had 1-5 members. About one in three of the peri-urban households had large households with 6 or more members $(33.1 \%)$. The corresponding proportion in rural households was $18.9 \%$. The majority of peri-urban households belonged to high economic status $(84.3 \%)$ compared to about one third $(34.7 \%)$ in the rural area. A large majority of the respondents had some form of formal education (84.3\%) with no variations across the study areas.

\begin{tabular}{llll}
\multicolumn{4}{l}{ Table 1: Household characteristics in rural and peri-urban areas (\%) } \\
\hline Variable & $\begin{array}{l}\text { Rural } \\
(\mathrm{n}=127)\end{array}$ & $\begin{array}{l}\text { Peri-urban } \\
(\mathrm{n}=121)\end{array}$ & $\begin{array}{l}\text { Total } \\
(\mathrm{n}=248)\end{array}$ \\
\hline Age & & & \\
$18-35$ & 33.1 & 46.2 & 39.5 \\
$36+$ & 66.9 & 53.7 & 60.5 \\
Sex & & & \\
Male & 45.7 & 37.2 & 41.5 \\
Female & 54.3 & 62.8 & 58.5 \\
$\begin{array}{l}\text { Household size } \\
\text { 1-5 }\end{array}$ & 81.1 & 66.9 & 74.5 \\
6+ & 18.9 & 33.1 & 25.5 \\
Economic status & & & \\
Poor & 65.3 & 15.7 & 41.1 \\
Non-poor & 34.7 & 84.3 & 58.9 \\
Education & & & \\
No formal & 17.3 & 14.0 & 15.7 \\
Formal & 82.7 & 86.0 & 84.3 \\
Ever visited for & & & \\
advice & & & \\
Yes & 32.1 & 52.8 & 41.1 \\
No & 67.9 & 47.2 & 58.9 \\
Type of latrine & & & \\
Type X & 3.1 & 0.8 & 2.0 \\
$\begin{array}{l}\text { Type A } \\
\text { Type B }\end{array}$ & 78.0 & 29.8 & 7.7 \\
Type C & 11.0 & 4.1 & 12.1 \\
Type D & 5.5 & 19.0 & 23.8 \\
\hline
\end{tabular}


Res. J. Environ. Earth Sci., 12(2): 19-28, 2020

Table 2: Perceived benefits of improved toilets $(n=248)$

\begin{tabular}{llllll}
\hline Benefits & Rural & Peri-urban & Total score & t-value & $\mathrm{p}$ \\
\hline Toilet use is more hygienic & 2.7 & 2.8 & 2.7 & -3.3 & 0.00 \\
Sharing of toilet is unhealthy & 2.5 & 2.6 & 2.5 & -2.2 & -2.9 \\
More comfortable & 2.7 & 2.8 & 2.7 & -3.8 & 0.02 \\
Provides privacy & 2.5 & 2.7 & 2.6 & -2.3 & 0.00 \\
Washable floor & 2.6 & 2.7 & 2.7 & -2.9 & 0.00 \\
Improves social status & 2.6 & 2.8 & 2.7 & -2.5 & 0.01 \\
Feels good when visited & 2.7 & 2.8 & 2.7 & -2.5 & 0.00 \\
Avoids unsightly environment & 2.7 & 2.8 & 2.8 & -2.4 & 0.5 \\
Gives more respect & 2.6 & 2.7 & 2.7 & -1.1 & 0.01 \\
More convenient during rainy season & 2.7 & 2.6 & 2.6 & -1.4 & 0.01 \\
Prevents house flies & 2.5 & 2.6 & 2.5 & -1.5 & 0.55 \\
Does not give bad smell & 2.5 & 2.5 & 2.6 & 2.6 & 0.27 \\
More convenient for women & 2.6 & 2.9 & 2.8 & 0.7 & 0.13 \\
Convenient at night & 2.7 & 2.5 & 2.6 & -0.7 & 0.00 \\
Convenient for ill and aged people & 2.6 & 2.5 & 2.5 & -0.3 & 0.46 \\
Prevents diarrheal diseases & 2.5 & 2.5 & 2.7 & -2.9 & 0.42 \\
Consistent with modern life & 2.7 & 2.7 & 2.6 & 0.75 \\
Overall & 2.6 & 2.7 & &
\end{tabular}

Means based on a three-point Likert scale: 1 = Disagree, 2 = Neutral, 3 = Agree

Less than half $(41.1 \%)$ of the households were visited for advice by the CLTS committee, with a relatively higher proportion in the peri-urban $(52.8 \%)$ than in the rural villages $(32.1 \%)$. Over half of the households (54.4\%) used type A latrines (78\% rural, $29.8 \%$ peri-urban). A relatively larger proportion (46.3\%) of the peri-urban households owned type D latrines compared to those in the rural areas $(2.4 \%)$. Similarly, nearly one in five peri-urban households used type $\mathrm{C}$ latrines while the corresponding figure for the rural households was only $5.5 \%$. Generally, type A latrines were more predominant in rural households whereas type $\mathrm{D}$ was more common in peri-urban households. These findings corroborate earlier observations by Mwakitalima et al. (2018) in Tanzania who found that type A latrines (traditional pit latrine) were the most common toilets used by about half (47.4\%) of rural households, followed by type D (pourflush toilet connected with septic tank), which accounted for $21.8 \%$ of the households. The observed wide-spread prevalence of unimproved toilets signifies unsafe disposal of human excreta. Lack of proper sanitation and hygiene affects the health of a community and subsequently impacts its potential for development (Ojo et al., 2017). These results highlight the long-term need for sanitation promotion if improved sanitation and community health outcomes are to be achieved.

Community perception of improved sanitation: The results from a 3-point Likert scale on the benefits of improved toilets in rural and peri-urban areas are shown in Table 2. Comparatively, improved toilets were perceived more positively in peri-urban than in rural areas. Except for the items 'more convenient while raining', 'more convenient for women', 'prevents flies from contaminating food' and 'improved latrine does not smell', the rest of benefits had significantly higher mean scores in peri-urban than in rural villages. The overall results show that mean scores of perceived benefits were high on 'avoid unsightly environment' and 'more convenient for women', each having a score of 2.8. Regarding the environment, participants reported that improved toilets help to avoid unsightly environment (feces) around the household which is consistent with a positive association between hygienic perception of toilets and the absence of visible feces (Lagerkvist et al., 2014). Generally, sanitation adoption is associated with cleanliness and a better home environment (Jenkins and Scott, 2007; Routray et al., 2015).

In this study, respondents indicated that the eruption of diarrhea diseases was among the reasons for constructing improved toilets. The average score of all elements was 2.6 which indicates that respondents scored 'agree' to most of the positive elements of improved toilet explored in this study. During interviews, a seventy-year woman stated that:

"Some years back, we had a traditional pit latrine here. Because of heavy rains, the latrine got damaged. I decided to build an improved toilet instead [...]. I was the first person to do so in this neighborhood. I feel very comfortable using this type of toilet. Many visitors come here to learn and I feel good about it"

Impliedly, the findings show that the perceived benefits of improved latrines were related to privacy and dignity. In rural Ethiopia, Novotný et al. (2018) reported that privacy was often cited as the most important factor for sustaining latrine use and upgrading latrines than for the initial shift from open defecation practices. In Ghana, Jenkins and Scott (2007) found that the most valued attributes for building a household toilet were cleanliness and that the concept of cleanliness was closely tied to the notion of beauty, respect, civility, pride, goodness and purity. Other attributes were convenience, comfort, promoting good health, safety/security, smell, easy to keep clean, avoid pests, visitor/guests, avoid sharing with others/strangers and prestige/pride. Such positive 
Res. J. Environ. Earth Sci., 12(2): 19-28, 2020

Table 3: Rotated pattern matrix for benefits of improved toilets $(n=248)$

\begin{tabular}{|c|c|c|c|c|}
\hline \multirow[b]{2}{*}{ Factor } & \multicolumn{4}{|c|}{ Rotated factor loadings } \\
\hline & 1 & 2 & 3 & 4 \\
\hline \multicolumn{5}{|l|}{$\overline{\text { Comfort }}$} \\
\hline Avoids unsightly environment & 0.934 & & 0.258 & 1.580 \\
\hline More comfortable & 0.934 & & 0.215 & 1.420 \\
\hline More hygienic & 0.851 & 0.111 & 0.187 & 0.153 \\
\hline \multicolumn{5}{|l|}{ Convenience } \\
\hline More convenient for women & & 0.912 & & 0.153 \\
\hline More convenient at night & 0.140 & 0.874 & 0.169 & 0.139 \\
\hline More convenient in the rainy season & 0.131 & 0.815 & 0.121 & \\
\hline \multicolumn{5}{|l|}{ Status symbol } \\
\hline Gives more respect & 0.187 & 0.128 & 0.793 & 0.175 \\
\hline Improves social status & 0.359 & 0.168 & 0.732 & \\
\hline Consistent with modern life & 0.120 & 0.191 & 0.575 & 0.482 \\
\hline \multicolumn{5}{|l|}{ Disease prevention } \\
\hline Prevents diarrhoea & 0.152 & & & 0.725 \\
\hline Prevents house flies & 0.225 & & & 0.659 \\
\hline$\underline{\text { Variance }}$ & 41.000 & 14.600 & 7.300 & 6.100 \\
\hline
\end{tabular}

qualities may invoke feelings of pride, which can further accentuate the adoption of improved sanitation. Viewed from the theory of planned behavior, it can be argued that the perceived benefits of improved sanitation were influenced by beliefs about the likely outcomes of the behavior and the evaluations of these outcomes. Similarly, beliefs about the normative expectations of others and motivation to comply with these expectations (e.g., gives more respect, consistent with modern life) were also key factors for households to adopt improved toilets.

Exploring motivations for improved sanitation using factor analysis: Table 3 shows the results of factor analysis for the perceived benefits of improved toilets. Based on Kaiser's criterion, four components with Eigen-values $>1$ were retained as separate factors. Variables with factor loadings $>0.5$ were considered to be important attributes in a given factor. The four extracted components explain $69 \%$ of the total variance. The first factor (component 1) explains $41 \%$ of the total variance. It represents comfort with variables like avoids unsightly environment, more comfortable and more hygiene, highly loading on this factor. Comfort is one of the most considered endowment factors valued by households that choose to adopt improved sanitation as previously reported in rural Benin (Jenkins and Curtis, 2005) and in urban slums of Nairobi Kenya (Lagerkvist et al., 2014). Further, comfort determines the use of latrine as one of the key informants stated:

"I think that people are always reluctant to use uncomfortable, smelly and dirty latrines. They would rather choose to defecate in the open if they can"

Within the framework of the theory of planned behavior, comfort could be seen as falling within the category of behavioral beliefs, which relate to the likely outcomes of the behavior and the evaluations of such outcomes (Mariwah and Drangert, 2011).

The second component relates to convenience and explains $14.6 \%$ of the total variance. Factors highly loading on this component include more convenient for women, more convenient at night and more convenient during the rainy season. Generally, convenience typically relates to aspects of ease of physical use and accessibility (Mara et al., 2010). Convenience is explained in terms of avoiding the long walk to open defecation sites and having a reliable and close place to go when aged and ill (Jones, 2013; Mariwah et al., 2017). In Odisha India, a latrine facility in the house (or compound) was more convenient and saved time in walking long distances in search of a proper and clean site to defecate (Routray et al., 2015). The concept of convenience may also be related to the notion of safety which entails people's preference to defecate in a safe place for reasons including physical protection from accidents, injuries and associated emotional fears (Isunju et al., 2011).

The third component accounts for $7.3 \%$ of the total variance. This component is highly loaded with three variables, namely: gives more respect, improves social status and consistent with modern life and, thus, could be interpreted as related to a status symbol or social dignity. This component also provides evidence for social influence processes, which occur when behaviors are encouraged or constrained due to injunctive norms; the very idea for which CLTS programs were designed (Shakya et al., 2015). It leverages concerns about people's desire to maintain social standing and avoid social judgments. Qualitative studies assessing community-led sanitation programs have pointed to the importance of social norms in the success of programs aiming to increase latrine ownership and usage around the world (O'Reilly and Louis, 2014; Galvin, 2015). Accordingly, it has been suggested that for latrine building to succeed, it must become normative within a community rather than a matter of individual 
Res. J. Environ. Earth Sci., 12(2): 19-28, 2020

Table 4: Percent of households with improved toilets and handwashing facilities $(\mathrm{n}=248)$

\begin{tabular}{llllll}
\hline Attribute & Rural $(\mathrm{n}=127)$ & Peri-urban $(\mathrm{n}=121)$ & Total $(\mathrm{n}=248)$ & $\chi^{2}$ value & $\mathrm{p}$ \\
\hline Household has a latrine & 96.9 & 99.2 & 98.0 & 1.60 & 0.19 \\
Latrine has intact roofing materials & 48.8 & 80.0 & 64.2 & 25.70 & 0.00 \\
Latrine has washable floor & 23.6 & 70.0 & 46.5 & 52.60 & 0.00 \\
Latrine has walls not transparent & 70.9 & 93.4 & 81.9 & 21.10 & 0.00 \\
Latrine not shared & 66.9 & 85.1 & 75.8 & 11.20 & 0.00 \\
Latrine has a sink & 4.1 & 53.3 & 28.4 & 72.50 & 0.00 \\
Latrine has vent & 8.1 & 74.7 & 37.0 & 89.20 & 0.00 \\
Door closes completely & 19.5 & 61.7 & 46.5 & 84.00 & 0.00 \\
Latrine has septic tank & 5.7 & 69.4 & 43.3 & 85.60 & 0.00 \\
Improved toilet & 18.9 & 5.8 & 4.4 & 64.30 & 0.00 \\
Handwashing facility & 3.1 & & & 1.01 & 0.31 \\
\hline
\end{tabular}

preference and the training has to focus more on groups rather than individuals (Muthoni and Kavale, 2015; Ezbakhe et al., 2019). This concept is coherent with the increasing realization that latrine construction is not only a household matter but essentially a public good (Msambazi and Beebe, 2010).

Indeed, consideration of social norms is critical in technology adoption. Ramani et al. (2012) indicated that social norms and expectations may drive latrine adoption more than the observed health benefits of toilets. In their study in Odisha India, Routray et al. (2015) found that a more modern status and dignity for both females and males were the factors behind the adoption of toilets. It is worth noting that like in other studies (Sahoo et al., 2015; Hulland et al., 2015), women in the study area reported a distinct need for visual privacy. The influence of women on other women in one's social network to build a latrine has also been observed. Not wanting to fall behind statuswise with others in their social group, they would persuade their husbands to build latrines (Ezbakhe et al., 2019). Women, therefore, may be regarded as key agents of demand for improved sanitation at the household level suggesting the need to regard this role in sanitation interventions.

The last component (component 4) explains 6.1\% of the total variance and is loaded with two variables: prevents diarrhea and prevents house flies. Thus, the component can be viewed as related to disease prevention. This reflects the widely accepted role of improved sanitation in preventing the spread of waterborne diseases such as diarrhea, thus, contributing to improved health outcomes (Benova et al., 2014; Stocks et al., 2014; Zin et al., 2015; Andres et al., 2017). Although some studies have reported that householders rarely adopt and use toilets for health-related reasons (Mara et al., 2010), our findings show that healthrelated concerns were also important in the study area.

Adoption of improved sanitation: The findings in Table 4 show that almost all surveyed households (98\%) had toilets of one type or the other with no significant variation $\left(\chi^{2}=1.6, p=0.19\right)$ between the rural and peri-urban households. However, improved toilets were more significantly $\left(\chi^{2}=64.3, p=0.00\right)$ prevalent in peri-urban compared to rural areas $(69.4 \%$ vs. 18.9). The use of improved latrines in the study area is comparatively higher than the national average of $19 \%$ but far lower than $99.8 \%$ in Njombe District (Safari et al., 2019). Except for handwashing facilities which showed no significant variation between the two locations $\left(\chi^{2}=1.01, p=0.31\right)$, all other attributes of improved toilets revealed significantly $(p=0.00)$ higher proportions in peri-urban than in rural households. Living in urban areas has been associated with high adoption of latrines partly because of the exposure to improved sanitation and because open defecation is difficult to practice in towns (Shakya et al., 2015). While access to improved sanitation has generally improved in recent years, progress has been uneven and available data highlight inequalities among and within districts (URT, 2016). In particular, the inequalities exist not only between rural and urban areas, poor and rich but also between vulnerable groups and the general population (Spuhler et al., 2018). Although our study did not assess sanitation status among the disadvantaged groups, studies have reported that such groups are often at the lower rung of the ladder (Reddy and Snehalatha, 2011; Wilbur and Danquah, 2015). Thus addressing and eliminating these inequalities should be the central concerns if access to improved sanitation is to become universal.

According to Routray et al. (2015), improved latrines are often adopted by community members who have some kind of exposure and knowledge of their advantages. Findings showed that during the triggering stage, communities in the rural areas were not engaged adequately. Only $49.1 \%$ of households in rural villages were ever inspected compared to $55.6 \%$ in peri-urban households. From the administrative perspective, a lack of financial incentivization, particularly in the rural areas, has been identified as a barrier to effective follow-up and technical support during a post-triggering stage of CLTS implementation (Perard, 2018). Transport challenges, also linked with poor financing, deter regular visits, especially in rural areas. Indeed, sanitation failure has been attributed to several factors including lack of ongoing support (Blackett et al., 2013), lack of user acceptance (Bao et al., 2013), lack of operation and maintenance plan and lack of technical support (Davis et al., 2019). These factors apply to the current study area, especially in rural areas. 
Res. J. Environ. Earth Sci., 12(2): 19-28, 2020

Table 5: Demographic and socio-economic factors associated with adoption of improved toilets $(\mathrm{n}=248)$

\begin{tabular}{|c|c|c|c|c|c|}
\hline Characteristic & Households in a category & Frequency of improved toilets & Percent within category & $\chi^{2}$ & $\mathrm{p}$ \\
\hline \multicolumn{6}{|l|}{ Age } \\
\hline $18-35$ & 98 & 51 & 52.0 & \multirow[t]{2}{*}{5.30} & \multirow[t]{2}{*}{0.02} \\
\hline $36+$ & 148 & 55 & 37.2 & & \\
\hline \multicolumn{6}{|l|}{ Sex } \\
\hline Male & 103 & 39 & 37.9 & \multirow{2}{*}{23.10} & \multirow[t]{2}{*}{0.12} \\
\hline Female & 145 & 69 & 47.6 & & \\
\hline \multicolumn{6}{|l|}{ Household size } \\
\hline $1-5$ & 184 & 72 & 39.1 & \multirow[t]{2}{*}{5.70} & \multirow[t]{2}{*}{0.01} \\
\hline $6+$ & 64 & 36 & 56.2 & & \\
\hline \multicolumn{6}{|c|}{ Main occupation } \\
\hline Farmer & 235 & 97 & 39.1 & \multirow[t]{3}{*}{10.50} & \multirow[t]{3}{*}{0.00} \\
\hline Employed & 7 & 5 & 74.1 & & \\
\hline Business & 6 & 6 & 100 & & \\
\hline \multicolumn{6}{|c|}{ Economic status } \\
\hline Poor & 133 & 29 & 42.3 & \multirow[t]{2}{*}{75.00} & \multirow[t]{2}{*}{0.00} \\
\hline Non-poor & 112 & 80 & 71.4 & & \\
\hline \multicolumn{6}{|c|}{ Education level } \\
\hline No schooling & 39 & 8 & 20.5 & \multirow{4}{*}{10.20} & \multirow[t]{3}{*}{0.00} \\
\hline Primary & 182 & 80 & 44.0 & & \\
\hline Secondary + & 18 & 18 & 85.7 & & \\
\hline \multicolumn{5}{|l|}{ Regular visits } & \\
\hline Yes & 68 & 38 & 55.9 & \multirow[t]{2}{*}{5.80} & \multirow[t]{2}{*}{0.01} \\
\hline No & 180 & 70 & 38.9 & & \\
\hline \multicolumn{6}{|c|}{ Place of residence } \\
\hline Rural & 127 & 24 & 18.9 & \multirow{3}{*}{64.30} & \multirow[t]{2}{*}{0.00} \\
\hline Peri-urban & 121 & 84 & 69.4 & & \\
\hline \multicolumn{5}{|c|}{ House ownership } & \\
\hline Owner & 27 & 15 & 44.4 & \multirow[t]{2}{*}{0.01} & \multirow[t]{2}{*}{0.92} \\
\hline$\underline{\text { Tenant }}$ & 221 & 125 & 43.4 & & \\
\hline
\end{tabular}

Further, enforcement of compliance to sanitation and hygiene standards was lacking except in Muhuwesi village. Analysis of improved toilets by village (data not shown) showed that coverage of improved toilets in Muhuwesi village was higher compared to the rest of the study areas. It is important to note that these factors have been identified in the literature as domains of how people access, negotiate and use sanitation services (Bisung and Dickin, 2019).

Factors associated with the adoption of improved sanitation: Results on the factors associated with the adoption of improved toilets are presented in Table 5. Chi-square test results revealed that favorable factors for the adoption of improved toilets included younger age (18-35 years) of household heads $\left(\chi^{2}=5.3\right.$, $p=0.02)$, large family $(6+$ members $)\left(\chi^{2}=5.7, p=0.01\right)$ and engagement in small business and formal employment $\left(\chi^{2}=10.5, p=0.00\right)$. Others were high economic status $\left(\chi^{2}=75, p=0.00\right)$ and secondary or higher education among household heads $\left(\chi^{2}=10.2\right.$, $p=0.00)$. Findings also showed that 68 households (27.4\% of total) had regular visits by the CLTS committees. Of these, $55.9 \%$ owned improved toilets while $44.1 \%$ didn't. On the other hand, 180 households (72.5\% of total) were not visited regularly among which only 70 households $(38.9 \%)$ owned improved toilets $\left(\chi^{2}=5.79, p=0.01\right)$. As observed earlier, living in peri-urban areas was significantly $\left(\chi^{2}=64.3\right.$, $p=0.00)$ associated with the adoption of improved latrines than living in rural areas. Overall, these factors relate to control beliefs related to factors that may facilitate or impede adoption and use of latrines as articulated in the theory of planned behavior.

A study by Tumwebaze et al. (2011) in Kabale, Uganda reported that respondents with tertiary and secondary education were 2-5 times more likely to have improved toilet facilities than respondents with primary education suggesting that education helps to overcome beliefs and perceptions hindering adoption of improved toilets. Non-poor households and a high level of education are most likely to have improved toilets. These factors affect the resources to build a toilet and the understanding of the reasons why having a toilet would be beneficial (Cameron et al., 2019). A large scale study in Tanzania revealed that the economic status of the household, education level of the household head and access to technical support were significantly associated with latrine adoption (Mwakitalima et al., 2018). Because promoting better sanitation is an intrinsically social process and hard to separate from local-political contexts and relations (McFarlane, 2012), there is a need for more sustained community engagement given the burden of sanitationrelated diseases. Evidence shows that long-term sanitation uptake after implementation has been a challenge in many contexts (Godfrey et al., 2014; Dickin et al., 2018). During interviews with householders across the villages, it was apparent that there were barriers of not having access to technical support which, therefore, threatens the sustainability of the CLTS intervention. 


\section{CONCLUSION AND RECOMMENDATIONS}

This study has assessed community perception and the determinants for the adoption of improved sanitation and hygiene in rural and peri-urban areas of Tunduru District. The results have shown that almost all surveyed households use toilet facilities of one type or another but improved toilets are perceived more positively by householders in peri-urban than in rural areas. Positive perception of improved toilets is attributed to the comfort, convenience, social status and dignity and disease prevention. The main factors associated with the adoption of improved sanitation are younger age of household heads, secondary or higher education, employment or engaging in small business, higher household economic status and living in periurban areas. More support on technical advice and income generation strategies are recommended to help communities adopt and use improved latrines. Indeed, the government in collaboration with non-state actors should continue to promote behavioral change by providing knowledge and increasing awareness on the importance of improved sanitation. Greater support from the Local Government Authority is especially necessary for collective decision making in favor of improved sanitation.

\section{ACKNOWLEDGMENT}

We express our sincere appreciation to all of our respondents for participating in this study.

\section{REFERENCES}

Ajzen, I., 2002. Residual effects of past on later behavior: Habituation and reasoned action perspectives. Pers. Soc. Psychol. Rev., 6(2): 107-122.

Alemu, F., A. Kumie, G. Medhin, T. Gebre and P. Godfrey, 2017. A socio-ecological analysis of barriers to the adoption, sustainablity and consistent use of sanitation facilities in rural Ethiopia. BMC Public Health, 17(1): 706.

Andres, L., B. Briceño, C. Chase and J.A. Echenique, 2017. Sanitation and externalities: Evidence from early childhood health in rural India. J. Water Sanit. Hyg. Dev., 7(2): 272-289.

Armah, F.A., B. Ekumah, D.O. Yawson, J.O. Odoi, A.R. Afitiri and F.E. Nyieku, 2018. Access to improved water and sanitation in sub-Saharan Africa in a quarter century. Heliyon, 4(11): e00931.

Augsburg, B. and P.A. Rodriguez-Lesmes, 2018. Sanitation and child health in India. World Dev., 107: 22-39.

Bao, P.N., T. Aramaki and K. Hanaki, 2013. Assessment of stakeholders' preferences towards sustainable sanitation scenarios. Water Environ. J., 27: 58-70.
Behera, B., D.B. Rahut and N. Sethi, 2020. Analysis of household access to drinking water, sanitation, and waste disposal services in urban areas of Nepal. Utilities Policy, 62: 100996.

Benova, L., O. Cumming, B.A. Gordon, M. Magoma and O.M.R. Campbell, 2014. Where there is no toilet: Water and sanitation environments of domestic and facility births in Tanzania. PLoS One, 9(9): e106738.

Bisung, E. and S. Dickin, 2019. Concept mapping: Engaging stakeholders to identify factors that contribute to empowerment in the water and sanitation sector in West Africa. SSM- Popul. Health, 9: 100490.

Blackett, I.C., K. Eales, E. Febriani and R.F. Siregar, 2013. Review of Community-managed Decentralized Wastewater Treatment Systems in Indonesia. Water and Sanitation Program: Technical Paper.

Cameron, L., S. Olivia and M. Shah, 2019. Scaling up sanitation: Evidence from an RCT in Indonesia. J. Dev. Econ., 138: 1-16.

Chung, S.M. and R.S. Hellberg, 2020. Effects of poor sanitation procedures on cross-contamination of animal species in ground meat products. Food Control, 109: 106927.

Davis, A., A. Javernick-Will and S.M. Cook, 2019. The use of qualitative comparative analysis to identify pathways to successful and failed sanitation systems. Sci. Total Environ., 663: 507-517.

Dickin, S., L. Dagerskog, A. Jiménez, K. Andersson and K. Savadogo, 2018. Understanding sustained use of ecological sanitation in rural Burkina Faso. Sci. Total Environ., 613: 140-148.

Ezbakhe, F., R. Giné-Garriga and A. Pérez-Foguet, 2019. Leaving no one behind: Evaluating access to water, sanitation and hygiene for vulnerable and marginalized groups. Sci. Total Environ., 683: 537-546.

Field, A., 2009. Discovering Statistics Using SPSS. 3rd Edn., Sage Publications, London.

Galvin, M., 2015. Talking shit: is community-led total sanitation a radical and revolutionary approach to sanitation? Wiley Interdiscip. Rev. Water, 2(1): 9-20.

Godfrey, S., M. van der Velden, A. Muianga, A. Xavier, K. Downs, C. Morgan and J. Bartram, 2014. Sustainability check: Five-year annual sustainability audits of the water supply and open defecation free status in the 'One Million Initiative', Mozambique. J. Water Sanit. Hyg. Dev., 4: 471-483.

Harter, M., N. Contzen and J. Inauen, 2019. The role of social identification for achieving an opendefecation free environment: A clusterrandomized, controlled trial of Community-Led Total Sanitation in Ghana. J. Environ. Psychol., 66: 101360. 
Hulland, K.R.S., R.P. Chase, B.A. Caruso, R. Swain, B. Biswal, K.C. Sahoo, P. Panigrahi and R. Dreibelbis, 2015. Sanitation, stress, and life stage: A systematic data collection study among women in Odisha, India. PloS One, 10(11).

Isunju, J.B., K. Schwartz, M.A. Schouten, W.P. Johnson and M.P. van Dijk, 2011. Socio-economic aspects of improved sanitation in slums: A review. Public Health, 125(6): 368-376.

Jenkins, M.W. and V. Curtis, 2005. Achieving the 'good life': Why some people want latrines in rural Benin. Soc. Sci. Med., 61: 2446-2459.

Jenkins, M.W. and B. Scott, 2007. Behavioral indicators of household decision-making and demand for sanitation and potential gains from social marketing in Ghana. Soc. Sci. Med., 64(12): 2427-2442.

Jiménez, A., F.F. Mtango and S. Cairncross, 2014. What role for local government in sanitation promotion? Lessons from Tanzania. Water Policy, 16(6): 1104-1120.

Jones, H., 2013. Mainstreaming Disability and Ageing in Water, Sanitation and Hygiene Programmes: A Mapping Study Carried out for WaterAid UK. Retrieved from: https://www.gov.uk/dfid-researchoutputs.

Lagerkvist, C.J., S. Kokko and N. Karanja, 2014. Health in perspective: Framing motivational factors for personal sanitation in urban slums in Nairobi, Kenya, using anchored best-worst scaling. J. Water Sanit. Hyg. Dev., 4(1): 108-119.

Mara, D., B. Scott and D. Trouba, 2010. Sanitation and Health. PLOS Med., 7(11): e1000363.

Mariwah, S. and J.O. Drangert, 2011. Community perceptions of human excreta as fertilizer in periurban agriculture in Ghana. Waste Manag. Res., 29(8): 815-822.

Mariwah, S., K. Hampshire and C. Owusu-Antwi, 2017. Getting a foot on the sanitation ladder: User satisfaction and willingness to pay for improved public toilets in Accra, Ghana. J. Water Sanit. Hyg. Dev., 7(3): 528-534.

McFarlane, C., 2012. From sanitation inequality to malevolent urbanism: The normalisation of suffering in Mumbai. Geoforum, 43(6): 1287-1290.

Msambazi, M. and A. Beebe, 2010. Latrine Construction Not Only a Household Matter but a Public a Public Good: Revolutionary Thinking to End a Long Standing Problem of Low Coverage of Improved Toilets in Tanzania. Retrieved from: https://washmatters.wateraid.org/publications. (Accessed on: February 5, 2020).

Muthoni, W.W. and S. Kavale, 2015. Factors influencing strategy implementation of water supply firms in Kenya: Case study of Mombasa water supply and sanitation limited. Int. J. Sci. Basic Appl. Res., 22(2): 191-211.
Mwakitalima, A., K. Massa, A. Seleman and T. Kassile, 2018. Scaling up rural sanitation in Tanzania: Evidence from the national sanitation campaign. J. Water Sanit. Hyg. Dev., 8(2): 290-306.

Novotný, J., H. Humňalová and J. Kolomazníková, 2018. The social and political construction of latrines in rural Ethiopia. J. Rural Stud., 63: 157-167.

Ojo, T.T., N.L. Hawley, M.M. Desai, A.R. Akiteng, D. Guwatudde and J.I. Schwartz, 2017. Exploring knowledge and attitudes toward noncommunicable diseases among village health teams in Eastern Uganda: A cross-sectional study. BMC Public Health, 17(1): 947.

Omambia, A.N., 2010. Sanitation in urban slums: Perception, attitude and behavior: The case of Kibera, Nairobi-Kenya. J. Environ. Sci. Eng., 4(3): 70 .

O'Reilly, K. and E. Louis, 2014. The toilet tripod: Understanding successful sanitation in rural India. Health Place, 29: 43-51.

Perard, E., 2018. Economic and financial aspects of the sanitation challenge: A practitioner approach. Utilities Policy, 52: 22-26.

Poortvliet, P.M., L. Sanders, J. Weijma and J.R. De Vries, 2018. Acceptance of new sanitation: The role of end-users' pro-environmental personal norms and risk and benefit perceptions. Water Res., 131: 90-99.

Prüss-Ustün, A., J. Bartram, T. Clasen, J.M. Colford Jr, O. Cumming, V. Curtis, M.C. Freeman et al., 2014. Burden of disease from inadequate water, sanitation and hygiene in low- and middle-income settings: A retrospective analysis of data from 145 countries. Trop. Med. Int. Health, 19(8): 894-905.

Ramani, S.V., S. SadreGhazi and G. Duysters, 2012. On the diffusion of toilets as bottom of the pyramid innovation: Lessons from sanitation entrepreneurs. Technol. Forecast. Soc., 79(4): 676-687.

Reddy, B.S. and M. Snehalatha, 2011. Sanitation and personal hygiene: What does it mean to poor and vulnerable women? Indian J. Gend. Stud., 18(3): 381-404.

Routray, P., W.P. Schmidt, S. Boisson, T. Clasen and M.W. Jenkins, 2015. Socio-cultural and behavioural factors constraining latrine adoption in rural coastal Odisha: An exploratory qualitative study. BMC Public Health, 15: 880.

Safari, J., H. Mohamed, P. Dimoso, W. Akyoo, F. Odhiambo, R. Mpete, K. Massa and A. Mwakitalima, 2019. Lessons learned from the national sanitation campaign in Njombe district, Tanzania. J. Water Sanit. Hyg. Dev., 9(4): 754-764.

Sahoo, K.C., K.R.S. Hulland, B.A. Caruso, R. Swain, M.C. Freeman, P. Panigrahi and R. Dreibelbis, 2015. Sanitation-related psychosocial stress: A grounded theory study of women across the lifecourse in Odisha, India. Soc. Sci. Med., 139: 80-89. 
Sclar, G.D., J.V. Garn, G. Penakalapati, K.T. Alexander, J. Krauss, M.C. Freeman, S. Boisson, K.O. Medlicott and T. Clasen, 2017. Effects of sanitation on cognitive development and school absence: A systematic review. Int. J. Hyg. Environ. Health, 220(6): 917-927.

Seleman, A. and M.G. Bhat, 2016. Multi-criteria assessment of sanitation technologies in rural Tanzania: Implications for program implementation, health and socio-economic improvements. Technol. Soc., 46: 70-79.

Shakya, H.B., N.A. Christakis and J.H. Fowler, 2015. Social network predictors of latrine ownership. Soc. Sci. Med., 125: 125-138.

Spuhler, D., A. Scheidegger and M. Maurer, 2018. Generation of sanitation system options for urban planning considering novel technologies. Water Res., 145: 259-278.

Stocks, M.E., S. Ogden, D. Haddad, D.G. Addiss, C. McGuire and M.C. Freeman, 2014. Effect of water, sanitation, and hygiene on the prevention of trachoma: A systematic review and meta-analysis. PLoS Med., 11: e1001605.

Tumwebaze, I.K., C.G. Orach, J.K. Nakayaga, C. Karamagi, C. Luethi and C. Niwagaba, 2011. Ecological sanitation coverage and factors affecting its uptake in Kabale municipality, western Uganda. Int. J. Environ. Health Res., 21(4): 294-305.

Tunduru District Council, 2018. Tunduru SocioEconomic Profile: Investment Opportunities in Tunduru District in Ruvuma Region. Retrieved from: www.tundurudc.go.tz.

UNICEF and WHO, 2016. Core Questions and Indicators for Monitoring WASH in Schools in the Sustainable Development Goals. Geneva: Switzerland.

URT (United Republic of Tanzania), 2015. Sanitation Monitoring Handbook for Households and Institutions: Tanzania Mainland. International Bank for Reconstruction and Development/the World Bank. Retrieved from: https://www.wsp.org. (Accessed on: Feb 6, 2020).
URT (United Republic of Tanzania), 2016. Tanzania 2015-2016 Demographic and Health Survey and Malaria Indicator Survey: Key Findings. MoHCDGEC, MoH, NBS, OCGS, and ICF, Rockville, Maryland, USA.

WHO/UNICEF, 2012.Water Sanitation Hygiene: Joint Monitoring Report. Key Terms On Safe DrinkingWater, Sanitation. Retrieved from: https://www.who.int/water_sanitation_health/monit oring. (Accessed on: Feb 6, 2020).

WHO/UNICEF, 2017. WASH in the 2030 Agenda: New Global Indicators for Drinking Water, Sanitation and Hygiene 2017. WHO/UNICEF Joint Monitoring Programme for Water Supply and Sanitation, World Health Organization, Geneva. Switzerland.

Wilbur, J. and L. Danquah, 2015. Undoing inequity: Water, sanitation and hygiene programmes that deliver for all in Uganda and Zambia-an early indication of trends. Proceeding of 38th WEDC International Conference. Loughborough University, UK.

Wolf, J., A. Pruss-Ustun, O. Cumming, J. Bartram, S. Bonjour and S. Cairncross, 2014. Assessing the impact of drinking water and sanitation on diarrhoeal disease in low- and middle-income settings: Systematic review and meta-regression. Trop. Med. Int. Health, 19: 928-942.

WSP, 2012. Water and Sanitation Program. Economics of Poor Sanitation in Africa. Water and Sanitation Programme Visit. Retrieved from: http://www.wsp.org/wsp/content/africa-economicimpacts-sanitation.

Wyatt, R.C. and L.S. Meyers, 1987. Psychometric properties of four 5-point likert-type response scales. Educ. Psychol. Meas., 47: 27-35.

Zin, T., T. Sabaiaung, S. Saupin, T. Myint, D. Khinsn, M.S. Aung and B.S. Shamsudin, 2015. Influencing factors for cholera and diarrhoea: Water sanitation and hygiene in impoverished rural villages of Beluran district, Sabah, Malaysia. Malaysian J. Public Health Med., 15(1): 30-40. 